\title{
e-interview
}

\section{Andrew Cheng}

Andrew Cheng is research fellow and professor at the Institute of Biomedical Sciences, Academia Sinica, Taipei, Taiwan. He trained in clinical psychiatry at the Department of Psychiatry, National Taiwan University Hospital, and in psychiatric research at the Institute of Psychiatry, London. His interests are epidemiological studies of suicide, affective disorders and alcoholism.

\section{If you were not a psychiatrist, what} would you do?

Definitely not another branch of medicine. If I could start again, I'd like to work on literature, poetry and other humanities.

What has been the greatest impact of your profession on you personally?

It has enabled me to obtain a better insight, to establish a healthy and constructive view of life, and a better understanding of human nature.

\section{Do you feel stigmatised by your profession?}

Not at all. On the contrary, medical professionals and the public see psychiatrists in Taiwan as increasingly important. This is because mental disorder (notably depression, suicide, drug and alcohol misuse and post-traumatic stress disorder) has now become a major social and public health issue.

\section{What are your interests outside of} work?

Classical music, reading, writing and travelling

Who was your most influential trainer, and why?

The late Professor Michael Shepherd was my most important mentor. He taught me how to study mental illness using an epidemiological approach.

What job gave you the most useful training experience?

Being a research psychiatrist at the Institute of Psychiatry, London (1979-1981).

Which book has influenced you most? Epidemiological Psychiatry by Brian Cooper and H. G. Morgan.

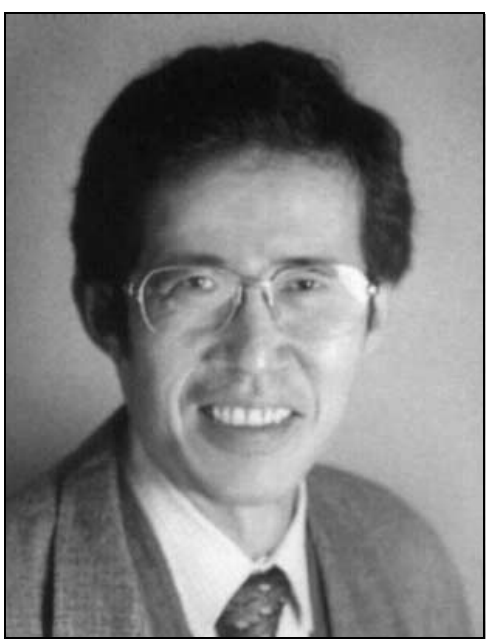

suited to the profession, the mainstream of psychiatry is still clear about the best means of service provision and doing research.

How would you entice more medical students into the profession? Offering good opportunities for them to observe and learn about the process of becoming mentally ill and its impact on individuals and society as a whole.

What is the most important advice you could offer to a new trainee?

A psychiatrist who does not have any interest in seeing patients can hardly become a competent clinician or researcher (excluding bench work)

What are the main ethical problems that psychiatrists will face in the future?

What research publication has had the greatest influence on your work? Shepherd, M. (1978) Epidemiology and clinical psychiatry. British Journal of Psychiatry, 133, 289-298.

What part of your work gives you the most satisfaction?

Service combined with psychiatric epidemiological research.

What do you least enjoy?

Administrative work and meetings.

What is the most promising opportunity facing the profession?

The crisis in the global economy and ethnic, political and military conflicts that will bring about more and more mental health problems requiring active psychiatric intervention.

\section{What is the greatest threat?}

Anti-psychiatry attitudes in mental health workers who do not have enough training in clinical psychiatry.

What single change would substantially improve quality of care? If all nations diverted military expenditure into mental health services in the community, including proper management of child abuse, unemployment and so forth

Do you think psychiatry is brainless or mindless?

Some colleagues might behave like this, but other than those who may not have been
Confidentiality for those who are mentally ill, abuse of psychiatry, informed consent for biological studies of mental illness, conflicts of interest with the pharmaceutical industry, and inappropriate genetic manipulation in mental illness.

How would you improve clinical psychiatric training?

Facilitate training in liaison psychiatry and primary care psychiatry.

What single change to mental health legislation would you like to see? An act to implement comprehensive community mental health care within the general medical care system, in conjunction with a proper social welfare policy and human rights protection.

How should the role of the Royal College of Psychiatrists change? To focus more on both academic and educational (for the profession and the public) responsibilities.

What single area of psychiatric Birth cohort studies to identify early environmental risk factors and their interaction with genetic vulnerability.

What single area of psychiatric practice is most in need of development? Primary care psychiatry. research should be given priority? 